\title{
UN MODERNO MUY ACTUAL
}

\section{Alberto Mario Damiani (UBA-UNR-CONICET)}

RESUMEN: El trabajo expone cronológicamente la influencia de la obra de Vico en la formación y el desarrollo de los intereses filosóficos e histórico-filosóficos del autor.

Palabras Clave: Vico, $350^{\circ}$ Aniversario, historia de la filosofía, actualidad, política, A.M. Damiani.

\section{A very actual modern}

ABSTRACT: The work exposes chronologically the influence of Vico's work on the formation and development of the author's philosophical and historical-philosophical interests.

KEYWORDs: Vico, $350^{\text {th }}$ Anniversary, history of philosophy, current affairs, politics, A.M. Damiani.

\section{Un moderno molto attuale}

RIASSUNTO: Il lavoro espone cronologicamente l'influenza dell'opera di Vico sulla formazione e lo sviluppo degli interessi filosofici e storico-filosofici dell'Autore.

PAROLE CHIAVE: Vico, $350^{\circ}$ Anniversario, storia della filosofia, attualità, politica, A.M. Damiani.

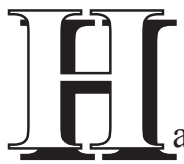

ace más de dos décadas comencé a interesarme por la obra de Giambattista Vico, porque encontré en ella un claro ejemplo del sentido propiamente filosófico del estudio de la historia de la filosofía. Eran tiempos en que todavía se caracterizaba nuestra época en términos de una presunta condition postmoderne. Para ello se postulaba una imagen monolítica de la modernidad, que no podía ser tomada en serio por quienes nos dedicábamos a la historia de la filosofía. En ese contexto, comprendí el De ratione como una intervención de nuestro filósofo en la célebre Querelle des anciens et des modernes y pude reconocer que la filosofía moderna no había tenido que esperar hasta 1979 para encontrar un crítico, sino que

Este artículo responde a una invitación expresa por parte de la Dirección de la Revista para este volumen especial por el $350^{\circ}$ Aniversario del nacimiento de G. Vico, habiendo superado los criterios de valoración y del proceso de aceptación. 
nació y continuó como una reflexión autocrítica. Del mismo modo, encontré en la Scienza nuova una teoría que desmentía la identificación apresurada de la idea de progreso con un componente esencial de la moderna filosofía de la historia. ${ }^{1}$

Este interés despertado por el descubrimiento de la actualidad de la obra de nuestro filósofo me condujo a examinar, por un lado, los presupuestos metafísicos de su ciencia sobre la naturaleza común de las naciones. En dicho examen reconocí en el principio verum ipsum factum y en la idea de una sapienza poetica las claves hermenéuticas de la historia, extraídas de una metafísica de la mente humana. Por otro lado, el mismo interés me llevó a encontrar en la retórica viquiana un primer intento de transformar el análisis del lenguaje persuasivo en un instrumento heurístico de una teoría universalista de la acción humana. Este hallazgo me permitió conectar de manera productiva la nouvelle rhétorique de Chaïm Perelman con la Transzendentalpragmatik de Karl-Otto Apel. ${ }^{2}$

El carácter común de la naturaleza de las naciones, demostrado por nuestro filósofo, me permitió advertir, por un lado, que con el giro historiográfico expresado en la correcta consigna programática de un Vico senza Hegel, se corrió el riesgo de no reconocer que la investigación filosófico-filológica propuesta por la Scienza nuova tampoco puede ser formulada en términos de la epistemología histórica del Verstehen. Por otro lado, la idea de un despliegue de la mente humana, que orienta el curso que siguen las naciones, me permitió contraponer la teología civil razona$d a$ de nuestro autor a los actuales intentos teológico-políticos de volver a reducir la filosofía a una anchilla teologiae. La comprensión que creí alcanzar entonces de la ubicación de la propuesta madura de Vico en la historia de la filosofía moderna me animó a presentar esa propuesta como una "ciencia anticartesiana", es decir, como una ciencia que presupone las críticas a Descartes que nuestro filósofo formuló en sus primeras obras. ${ }^{3}$

La afirmación del anticartesianismo de Vico, sin embargo, no me condenó a confundirlo con un adversario del racionalismo moderno, sino que pude reconocer en su obra la introducción de una estrategia argumentativa contra el escepticismo, más eficaz que la utilizada por René Descartes y por Hugo Grocio. El examen de esta estrategia unificada para refutar al escepticismo, tanto en el plano gnoseológico como en el plano político, me permitió prestarle especial atención, por un lado, al particular significado que Vico le asigna a la expresión "filosofía política", comprendida no como una disciplina filosófica, sino como un tipo de filosofía que comparte sus principios con los legisladores y se propone orientar las acciones de los autores del mundo civil. Por otro lado, dicho examen me condujo a estudiar los pre-

1. Cfr. DAMiani 1991, 1993.

2. Cfr. Damiani 1995/6, 1997 a, 2000 a, 2006.

3. Cfr. Damiani 1997 b, 2000 b, 2000 c. 
supuestos antropológicos de la política en la obra de nuestro filósofo. Estos resultados me permitieron formular una interpretación sistemática de la scienza viquiana como una disciplina que pretende orientar el gobierno racional del mundo civil mediante el conocimiento universal de sus condiciones antropológicas, institucionales y lingüísticas. ${ }^{4}$

El estudio de las condiciones lingüísticas que, según nuestro autor, permiten establecer y garantizar la correspondencia entre conocimiento y voluntad, entre ideas e instituciones, entre mundo metafísico de las mentes y mundo civil de los ánimos, me permitió reconocerlo no solo como un crítico de la filosofía de la conciencia moderna (de Descartes a Husserl), sino también como un importante antecedente del denominado giro lingüístico de la filosofía contemporánea. Este reconocimiento, sin embargo, no me llevó a contentarme con destacar otro elemento más de la herencia que hemos recibido de un autor siempre identificado como precursor de ideas y teorías de los siglos XIX y XX, sino que preferí tomarme en serio el desarrollo filosófico acaecido desde 1744 hasta nuestros días, atendiendo a diversas discusiones en torno a las verdaderas consecuencias del mencionado giro, a fin de tratar de identificar una perspectiva filosófica actual, que sea consecuente con la scienza viquiana.

Asumí que dicha perspectiva remite a principios universales que regulan el mundo civil intersubjetivo, instituido lingüísticamente durante lo que Vico denominaba "la edad de los hombres". En esta edad, las imágenes fantásticas de la sabiduría poética ya han perdido su fuerza persuasiva y la vida en común depende de los acuerdos alcanzados por hablantes que se saben autores responsables de las instituciones del mundo civil. Luego de descartar la hermenéutica filosófica contemporánea, por su rechazo anti-ilustrado al reconocimiento de principios universales, presupuestos en el uso del lenguaje, me dediqué varios años a explorar reflexivamente el saber de la acción (Handlungswissen) necesariamente presupuesto en la parte performativa de nuestros actos de habla. Esa exploración trascendental no solo tenía su punto de partida en el reconocimiento viquiano de las condiciones lingüísticas del mundo humano, sino que en su desarrollo volví a encontrar tesis de nuestro filósofo: por ejemplo, la idea del ser humano como "partícipe de la razón", o el carácter para nosotros incognoscible de la realidad natural, derivado del principio verum ipsum factum, carácter que podía ahora cuestionar gracias a la aplicación de la máxima pragmática de Charles Sanders Peirce. Uno de los últimos resultados a los que llegué con dicha exploración consiste en la aclaración de la diferencia y de la relación entre las reglas discursivas y las normas morales. ${ }^{5}$

La mencionada exploración reflexiva me permitió asumir una perspectiva filosófica muy útil para volver a examinar algunos problemas formulados por Vico

4. Cfr. Damiani $2000 \mathrm{~d}, 2001,2004,2005$.

5. Cfr. Damiani 2003, 2009, 2016.

Cuadernos sobre Vico 32 (2018) 
en sus obras. En primer lugar, el problema del conocimiento reflexivo en la obra de Vico, considerando el origen histórico-político de la autoconciencia, el sentido político de la máxima "nosce te ipsum", como expresión de un momento del desarrollo histórico de la racionalidad humana, y la reflexión necesaria para fundamentar epistemológicamente la scienza viquiana. En segundo lugar, el problema de la conexión entre instituciones artificiales y sociabilidad natural en Vico, considerando sus críticas a Grocio, la compatibilidad de la sociabilidad natural con el stato ferino y la inserción histórica de la naturaleza humana en las instituciones del mundo civil. Por último, el problema del futuro del ser humano desde una perspectiva filosófico-política, considerando el significado del concepto viquiano de humanidad y el del futuro como problema filosófico-político. ${ }^{6}$

Comencé diciendo que me interesé inicialmente en la obra de Giambattista Vico porque encontré en ella un claro ejemplo del sentido propiamente filosófico del estudio de la historia de la filosofía. Quisiera terminar este breve relato autobiográfico, sobre la influencia que ejerció Vico en mi formación, explicitando lo que entiendo por ese sentido filosófico de la historia de la filosofía. Un aspecto típico del pensamiento filosófico consiste en la relación con su propia historia. En las demás actividades humanas, muchas de las soluciones encontradas en el pasado para superar dificultades resultan, a la larga, sustituidas por soluciones preferibles y son olvidadas por quienes realizan esas actividades. Esas soluciones son solo objeto de una curiosidad histórica. Algo así no ocurre en filosofía, porque las propuestas de solución a los problemas filosóficos no solo deben poder ser defendidas frente a las objeciones actuales, sino también frente a los argumentos contenidos en las obras filosóficas clásicas. La vigencia permanente de estos argumentos radica en que resulta razonable siempre alegarlos o discutirlos en el debate filosófico contemporáneo. El diálogo filosófico tiene como interlocutores no solo a los filósofos actuales, sino también a los clásicos, esos interlocutores privilegiados, que vivieron en los siglos pasados y nos legaron las obras que hoy estudiamos. Para decirlo con unos versos de Quevedo, que le gustaba recitar a mi padre:

«Retirado en la paz de estos desiertos, con pocos, pero doctos libros juntos, vivo en conversación con los difuntos, y escucho con mis ojos a los muertos.»

Al igual que los demás participantes de este volumen, escucho con mis ojos a nuestro filósofo.

6. Cfr. DAMIANI 2009/10, 2014/15, 2016/17. 


\section{Bibliografía viquiana de Alberto Mario Damiani}

- (1991) «Vico y la autocrítica de la modernidad», Cuadernos de ética, nº 11-12, pp. 147-150.

— (1993) «Teoría y praxis en De nostri temporis studiorum ratione», Cuadernos sobre Vico, $\mathrm{n}^{\circ} 3,1993, \mathrm{pp} .53-$ 66.

— (1995/6) «Hermenéutica y metafísica en la Scienza nuova», Cuadernos sobre Vico, n 5/6, 1995-1996, pp. 5165.

- (1997 a) «Teoría de la argumentación y ética discursiva», Revista de Filosofia, 18, pp. 187-216.

— (1997 b) «Vico y Dilthey. La comprensión del mundo histórico», Cuadernos sobre Vico, nº 7/8, 1997, pp. 357375.

- (2000 a) «Las dos perspectivas de la retórica viquiana: Institutiones y Scienza», en: F. RATTO (ED.), Il mondo di Vico/Vico nel mondo, Guerra, Perugia, 2000, pp. 295-305.

- (2000 b) «La secolarizzazione politica nella Scienza Nuova», Bollettino del Centro di studi vichiani, XXX, 2000, pp. 213-229.

- (2000 c) Giambattista Vico. La ciencia anticartesiana, Buenos Aires, Almagesto, 2000, 184 págs.

- (2000 d) «Vico y la estrategia racionalista», Endoxa, n 13, pp. 121-132.

- (2001) «El concepto viquiano de "filosofía política"», en: E Hidalgo-Serna, M. Marassi, J. M. SeVILla, J. Villalobos (EDS.), Pensar para el nuevo siglo. Giambattista Vico y la cultura europea, Nápoles, Edizioni La Città del Sole, 2001, vol. II, pp. 775-795.

- (2003) «Humanismo civil y hermenéutica filosófica. Gadamer lector de Vico", Cuadernos sobre Vico, 15/16, 2003, pp. 31-47.

- (2004) «Il governo degli animi. I presuposti antropologici della politica in Giambattista Vico", en: M. MartiRAno, G. CACCIATORE (COMPS.), Vico nelle culture iberiche e lusitane, Guida Editore, Nápoles, 2004, pp. 185-202.

- (2005) Domesticar a los gigantes. Sentido y praxis en Vico, UNR Editora, Rosario, 2005.

- (2006) «Transzendentalphilosophie nach der Neuen Rhetorik», en: Josef Kopperschmidt (HrsG.), Die neue Rhetorik. Studien zu Chaim Perelman, Fink Verlag, Múnich, 2006, pp. 333-344.

- (2009) Handlungswissen. Eine transzendentale Erkundung nach der sprachpragmatischen Wende, Verlag Karl Alber, Friburgo/Múnich, 2009.

- (2009/10) «Nosce te ipsum. Reflexión y política en Vico», Cuadernos sobre Vico, n² 23/24, 2009-2010, pp. 133150 .

— (2014/15) «Instituciones artificiales y sociabilidad natural en Vico», Cuadernos sobre Vico, 28/29, 2014-2015, pp. 15-30.

- (2016) «Reglas discursivas y normas morales», Revista de Filosofia, 41, 1, pp. 7-31.

- $(2016 / 17)$ «El futuro de la humanidad en la filosofía política de Giambattista Vico», Cuadernos sobre Vico, $\mathrm{n}^{\circ}$ 30/31, 2016-2017, pp. 105-119.

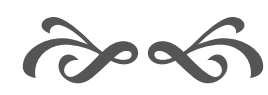


<smiles>[As]</smiles> 